ORIGINAL ARTICLE

\title{
Different dyspnoea perception in COPD patients with frequent and infrequent exacerbations
}

\author{
Giulia Scioscia, 1,2 Isabel Blanco, 1,3,4,5 Ebymar Arismendi, ${ }^{3,4}$ Felip Burgos, 1,3,4,5 \\ Concepción Gistau, ${ }^{1}$ Maria Pia Foschino Barbaro, ${ }^{2}$ Bartolome Celli, ${ }^{6}$ \\ Denis E O'Donnell, ${ }^{7}$ Alvar Agustí ${ }^{1,3,4,5}$
}

For numbered affiliations see end of article.

\section{Correspondence to} Dr Alvar Agustí, Respiratory Institute, Hospital Clínic, Villarroel, 170, Barcelona 08036, Spain; aagusti@clinic. ub.es

Received 14 January 2016 Revised 10 August 2016 Accepted 13 August 2016 Published Online First

1 September 2016

\section{SLinked}

- http://dx.doi.org/10.1136 thoraxjnl-2016-209318

\section{CrossMark}

To cite: Scioscia $\mathrm{G}$, Blanco I, Arismendi E, et al. Thorax 2017:72:117-121.

\section{ABSTRACT}

Background Some patients with COPD report frequent acute exacerbations (AECOPD) of the disease (FE), whereas others suffer them infrequently (IE). Because the current diagnosis of exacerbation relies on patient's perception of increased symptoms (mostly dyspnoea), we hypothesised that dyspnoea perception might be different in COPD patients with FE ( $\geq 2$ exacerbations or 1 hospitalisation due to AECOPD in the previous year) or IE ( $\leq 1$ exacerbation in the previous year), AECOPD being defined by the institution antibiotics and/or steroids treatment, or hospital admission.

Objective To test the hypothesis that dyspnoea perception is increased in FE and/or decreased in IE with COPD.

Methods We compared the perception of dyspnoea (Borg scale), mouth occlusion pressure $0.1 \mathrm{~s}$ after the onset of inspiration $\left(\mathrm{P}_{0.1}\right)$ and ventilatory response to hypercapnia $\left(\Delta \mathrm{V}_{\mathrm{E}} / \Delta \mathrm{P}_{\mathrm{ET}} \mathrm{CO}_{2}\right)$ in 34 clinically stable COPD patients with $F E(n=14)$ or IE $(n=20)$, with similar age, gender, body mass index and degree of airflow limitation. As a reference, we studied a group of age-matched healthy volunteers $(n=10)$ with normal spirometry.

Results At rest, $P_{0.1}$ was higher in FE than IE and controls $(p<0.01)$. Compared with controls, the ventilatory response to hypercapnia was equally blunted both in FE and IE $(p<0.001)$. Despite similar spirometry, during rebreathing peak Borg score and $\triangle B$ Borg were higher $(p<0.01)$ in $F E$ and lower $(p<0.01)$ in IE, than in controls.

Conclusions Dyspnoea perception during $\mathrm{CO}_{2}$ rebreathing is enhanced in $\mathrm{FE}$ and blunted in IE. These differences may contribute to the differential rate of reported exacerbations in FE and IE.

Trial registration number NCT02113839.

\section{INTRODUCTION}

The natural history of COPD is punctuated by episodes of acute worsening of symptoms, so-called acute exacerbations of COPD (AECOPD). ${ }^{1}$ These episodes are clinically relevant because they accelerate lung function decline, reduce physical activity, are associated with poorer quality of life and increase the risk of death of these patients. ${ }^{1}$ Besides, AECOPD are responsible for a large proportion of the healthcare costs attributable to COPD. ${ }^{1}$

\section{Key messages}

What is the key question?

- Do all patients with COPD perceive dyspnoea similarly?

What is the bottom line?

- Patients with COPD and frequent exacerbations perceive dyspnoea differently than those without frequent exacerbations.

\section{Why read on?}

- To learn the novel relationship between dyspnoea perception and frequency of exacerbations in COPD.

The pathobiology of AECOPD is still unclear in many aspects, ${ }^{2}$ and for reasons that are also not well defined, some patients with COPD have frequent episodes of AECOPD (FE), whereas others suffer them infrequently (IE). ${ }^{2}{ }^{3}$ Given that the diagnosis of AECOPD currently relies almost entirely on the patient's perception of an acute increase of symptoms (mostly breathlessness), ${ }^{4}$ we hypothesised that dyspnoea perception might be different in FE and IE. More specifically, we reasoned that overperception of dyspnoea might be associated with FE, whereas poor perception may be related to IE after accounting for possible between-group differences in respiratory mechanics and arterial blood gases. To explore this hypothesis, we compared the perception of dyspnoea during $\mathrm{CO}_{2}$ rebreathing in COPD patients with FE and IE. Some of the results of this study have been previously reported in abstract form.

\section{METHODS}

\section{Study design and ethics}

This observational, cross-sectional analysis of prospectively enrolled study participants was approved by the Ethics Committee of our institution, and all participants signed their informed consent (V.2.0 from April 2014), which was obtained according to the requirements of the Ethics Committee of the Hospital Clínic, Universitat de Barcelona (protocol HCP/14/329). The study was registered at clincaltrial.gov (NCT02113839). 


\section{Population}

We studied 34 patients with COPD who had been clinically stable during 3 months before testing. The diagnosis of COPD was established according to the Global Initative for Chronic Obstructive Lung Disease (GOLD) recommendations. ${ }^{1}$ Patients were classified as FE $(n=14)$ if they reported $\geq 2$ exacerbations (or required 1 hospitalisation because of AECOPD) in the previous year or as IE $(n=20)$ if they had $\leq 1$ exacerbation. ${ }^{1}$ AECOPD was defined by the need of treatment with antibiotics and/or steroids, or admission to hospital. ${ }^{1}$ Patients with unstable medical conditions, respiratory failure, congestive heart failure, coronary artery disease, neuromuscular diseases, severe psychiatric illness and/or receiving treatment with sedatives were excluded. We also studied 10 never or former smokers ( $>1$ year after cessation) with normal spirometry, matched for age, sex and body mass index (BMI) who served as controls.

\section{Measurements}

Forced spirometry (before and after bronchodilation), plethysmographic lung volumes, diffusion capacity for carbon monoxide ( $\mathrm{DL}_{\mathrm{CO}}$ ) (Medisoft body box, Surennes, Belgium) and arterial blood gases (Rapid point 500, Siemens Healthcare, Illinois, USA) were determined following international standards in all patients; ${ }^{6-8}$ in controls, only spirometry was measured. Reference values were those of a Mediterranean population. ${ }^{9-11}$

Maximum inspiratory pressure (MIP) and maximum expiratory pressure (MEP) were measured in 24 patients with COPD and 6 controls following the American Thoracic Society/ European Respiratory Society (ATS/ERS) recommendations. ${ }^{12}$ Mouth occlusion pressure $\left(\mathrm{P}_{0.1}\right)$ was measured at baseline, but not during rebreathing due to software limitations, following the ATS/ERS recommendations. ${ }^{12}$ Briefly, the inspiratory valve (Medisoft Hypaier, Surennes, Belgium) was occluded automatically at random intervals, without previous subject's knowledge, every two to six respiratory cycles. In each participant, we obtained a minimum of $10 \mathrm{P}_{0.1}$ measurements and the average of the 4 that differed by $<5 \%$ was used for analysis.

The ventilatory response to hypercapnia was determined following the Duffin rebreathing method. ${ }^{13}$ Briefly, while seated comfortably, participants breathed through a closed circuit from a rubber bag containing a gas mixture of $5 \% \mathrm{CO}_{2}$ and $95 \% \mathrm{O}_{2}$. The volume of gas in the rebreathing bag (4-5 L) was estimated from the vital capacity measured previously in each patient. Patients breathed room air quietly for a few minutes; then we opened the inspiratory valve and asked the patients to breathe in and out side the bag at their own pace. The rebreathing test was stopped when the participant could not continue it because of dyspnoea, $\mathrm{P}_{\mathrm{ET}} \mathrm{CO}_{2}>60 \mathrm{~mm} \mathrm{Hg}$ and/or after $4 \mathrm{~min}$, as recommended. ${ }^{14}$ After appropriate calibration, during the test we measured continuously end-tidal $\mathrm{PCO}_{2} \quad\left(\mathrm{P}_{\mathrm{ET}} \mathrm{CO}_{2}\right) \quad$ (Medisoft Hypaier), and mouth flow using a pneumotachograph (Medisoft Hypaier), from which minute ventilation $\left(\mathrm{V}_{\mathrm{E}}\right)$, tidal volume $\left(V_{T}\right)$ and respiratory rate (RR) were calculated (Medisoft Expair, Surennes, Belgium). The patient was asked to rate the level of dyspnoea perceived at rest and peak ventilation using the Borg scale. $^{15}$

\section{Statistical analysis}

Since this was a pilot study aimed at exploring our working hypothesis, we did not formally calculate a minimum sample size. Yet, similar studies published previously investigated similar number of patients. ${ }^{16}$ Results are presented as mean \pm SD or proportion. We used the Kruskal-Wallis test to compare controls, FE and IE, followed ad hoc by all pair-wise comparison using Mann-Whitney $U$ test with Bonferroni adjustment for multiple comparison. The $\chi^{2}$ test was used to compare categorical variables. A p value $<0.05$ was considered statistically significant. Data analysis was carried out using SPSS V.20.0 (Chicago, Illinois, USA).

\section{RESULTS}

Figure 1 presents the consort diagram of the study, and table 1 the main demographic, clinical and functional characteristics of participants finally included in the analysis. Age, gender distribution and BMI were similar in patients and controls. Cumulative smoking exposure was lower in controls, but packyears and proportion of current smokers were similar in FE and IE (table 1). The proportion of patients treated with long-acting bronchodilators and/or inhaled steroids tended to be numerically higher in FE, but differences were not statistically significant (table 1). The most frequent comorbidities identified in patients with COPD were diabetes mellitus, arterial hypertension, dyslipidemia, osteoporosis, gastro-oesophageal reflux and peripheral vascular disease.

On average, patients with COPD had severe airflow limitation, whereas, by definition, spirometry was normal in controls (table 1). There were no statistically significant differences in the severity of airflow limitation between FE and IE patients with COPD, although the distribution of GOLD grades of severity
Figure 1 Consort diagram of the study. AECOPD, acute exacerbation COPD.
41 consecutive COPD patients were screened in the Lung Function Laboratory

3 patients presented comorbidities (congestive heart failure, and coronary artery disease)
4 patients required one hospitalization for AECOPD 3 months before screening
14 patients were Frequent Exacerbators
20 patients were Infrequent Exacerbators 
tended to be shifted towards more severe grades in FE (table 1). In keeping with this, FE tended to have more lung hyperinflation and gas trapping than IE, although differences failed to reach statistical significance (table 1). Arterial blood gases, $\mathrm{DL}_{\mathrm{CO}}$, MIP and MEP values were similar in FE and IE (table 1).

Table 1 Main demographic, clinical and functional characteristics of participants

\begin{tabular}{|c|c|c|c|}
\hline & $\begin{array}{l}\text { Controls } \\
\mathrm{N}=10\end{array}$ & $\begin{array}{l}\text { COPD FE } \\
\mathrm{N}=14\end{array}$ & $\begin{array}{l}\text { COPD IE } \\
\mathrm{N}=20\end{array}$ \\
\hline \multicolumn{4}{|c|}{ Demographic and clinical characteristics } \\
\hline Age. years & $63 \pm 6$ & $65 \pm 9$ & $65 \pm 10$ \\
\hline Males, n (\%) & $8(80 \%)$ & $12(86 \%)$ & $17(85 \%)$ \\
\hline BMI, $\mathrm{kg} / \mathrm{m}^{2}$ & $29 \pm 4$ & $27 \pm 5$ & $27 \pm 7$ \\
\hline Current smokers, n (\%) & 0 & $4(29 \%)$ & $7(35 \%)$ \\
\hline Former smokers, $\mathrm{n}(\%)$ & $4(40 \%)$ & $10(71 \%)$ & $13(65 \%)$ \\
\hline $\begin{array}{l}\text { Cumulative smoking exposure } \\
\text { (packs/year) }\end{array}$ & $25 \pm 11$ & $52 \pm 25$ & $55 \pm 34$ \\
\hline LAMA, n (\%) & - & $14(100 \%)$ & $17(85 \%)$ \\
\hline LABA, n (\%) & - & $13(93 \%)$ & $16(80 \%)$ \\
\hline ICS, n (\%) & - & $13(93 \%)$ & $15(75 \%)$ \\
\hline \multicolumn{4}{|l|}{ Lung function } \\
\hline $\mathrm{FEV}_{1} / \mathrm{FVC}, \%$ & $0.79 \pm 0.42$ & $0.39 \pm 0.10$ & $0.43 \pm 0.19$ \\
\hline $\mathrm{FEV}_{1}, \%$ predicted & $100 \pm 14$ & $39 \pm 13$ & $45 \pm 16$ \\
\hline GOLD II, n (\%) & - & $3(21 \%)$ & $10(50 \%)$ \\
\hline GOLD III, n (\%) & - & $6(43 \%)$ & $6(30 \%)$ \\
\hline GOLD IV, n (\%) & - & $5(36 \%)$ & $4(20 \%)$ \\
\hline IC, \% predicted & - & $64 \pm 12$ & $61 \pm 12$ \\
\hline TLC, \% predicted & - & $117 \pm 12$ & $108 \pm 15$ \\
\hline $\mathrm{IC} / \mathrm{TLC}, \%$ & - & $0.55 \pm 0.12$ & $0.57 \pm 0.13$ \\
\hline FRC, \% predicted & - & $162 \pm 29$ & $149 \pm 33$ \\
\hline RV, \% predicted & - & $192 \pm 47$ & $160 \pm 50$ \\
\hline $\mathrm{DL}_{\mathrm{CO}}, \%$ predicted & - & $49 \pm 13$ & $50 \pm 17$ \\
\hline $\mathrm{PaO}_{2}, \mathrm{~mm} \mathrm{Hg}$ & - & $73.83 \pm 7.92$ & $73.48 \pm 8.61$ \\
\hline $\mathrm{PaCO}_{2}, \mathrm{~mm} \mathrm{Hg}$ & - & $39.06 \pm 3.02$ & $40.36 \pm 5.09$ \\
\hline \multicolumn{4}{|l|}{ Respiratory muscle function } \\
\hline MIP, \% predicted & $89.60 \pm 24.79$ & $72.60 \pm 25.47$ & $68.83 \pm 23.45$ \\
\hline MEP, \% predicted & $86.40 \pm 16.95$ & $70.64 \pm 17.89$ & $69.54 \pm 21.86$ \\
\hline \multicolumn{4}{|c|}{$\begin{array}{l}\text { Results are expressed as mean } \pm \text { SD. } \\
B M I \text {, body mass index; } D L_{C O} \text {, single-breath diffusing capacity for carbon monoxide; } \\
\mathrm{FE} \text {, frequent exacerbation; FRC, functional residual capacity; IC, inspiratory capacity; } \\
\text { ICS, inhaled corticosteroids; IE, infrequent exacerbation; LABA, long-acting } \\
\beta_{2} \text {-agonists; LAMA, long-acting muscarinic antagonists; MEP, maximal expiratory } \\
\text { pressure (although they were not measured in all the subjects); MIP, maximal } \\
\text { inspiratory pressure; RV, residual volume; TLC, total lung volume. }\end{array}$} \\
\hline
\end{tabular}

At baseline (before $\mathrm{CO}_{2}$ rebreathing), $\mathrm{RR}, \mathrm{V}_{\mathrm{T}}, \mathrm{V}_{\mathrm{E}}$ and $\mathrm{P}_{\mathrm{ET}} \mathrm{CO}_{2}$ were similar in all groups (table 2). The Borg score was numerically higher in patients with COPD than in controls, but differences did not reach statistical significance (table 2). $\mathrm{P}_{0.1}$ was higher than controls in both groups of patients with COPD $(\mathrm{p}<0.001)$, particularly in FE $(\mathrm{p}<0.01)$ (table 2$)$.

The duration of the rebreathing test was similar in all groups (table 3). As depicted graphically in figure 2, the ventilatory response to $\mathrm{CO}_{2}\left(\Delta \mathrm{V}_{\mathrm{E}} / \Delta \mathrm{P}_{\mathrm{ET}} \mathrm{CO}_{2}\right)$ was blunted $(\mathrm{p}<0.01)$ in both groups of patients with COPD versus controls, without statistically significant differences between FE and IE $(p=0.08)$ (table 3). At peak rebreathing, RR was similar across groups (table 3) but patients with COPD exhibited lower $V_{T}$ and $V_{E}$ values than controls (without significant differences between $\mathrm{FE}$ and IE), despite higher $\mathrm{P}_{\mathrm{ET}} \mathrm{CO}_{2}$ (table 3 and figure 3). Controls achieved a $\mathrm{V}_{\mathrm{T}}$ plateau at higher $\mathrm{V}_{\mathrm{E}}$ values than patients with COPD, but there were no differences between FE and IE (figure 3). As shown in figure 4, compared with controls, Borg score at peak ventilation (and $\Delta$ Borg from baseline (table 3 )) was significantly higher in FE but reduced in IE.

\section{DISCUSSION}

The results of this study confirm our working hypothesis and show that dyspnoea perception during $\mathrm{CO}_{2}$ rebreathing is different in COPD patients with FE (enhanced) and IE (blunted).

In keeping with previous studies, ${ }^{16-18}$ we observed that the ventilatory response to hypercapnia was blunted (figure 2), and the resting $\mathrm{P}_{0.1}$ value increased (table 2), in patients with COPD versus controls. Our results extend these previous reports, for the first time to our knowledge, to FE and IE whose perception of dyspnoea, as assessed by both the Borg score at peak ventilation (figure 4 ) and $\Delta$ Borg (table 3 ), was also significantly different. The fact that these were increased in FE but reduced in IE versus controls (table 2 and figure 2) suggests different operating mechanisms of dyspnoea perception in FE and IE.

Mechanisms underlying dyspnoea perception in humans involve a complex chain of events that require the cortical integration of several afferent/efferent signals coloured by affective processing. ${ }^{19-21}$ Changes in lung mechanics are an important afferent signal in this system. ${ }^{19-21}$ Although differences did not reach statistical significance, patients with $\mathrm{FE}$ tended to have more lung hyperinflation and air trapping at rest (table 1) and showed a smaller tidal volume expansion during chemostimulation (table 2) than IE. In theory, therefore, a greater mechanical constraint and earlier neuromechanical dissociation during $\mathrm{CO}_{2}$ rebreathing may underlie the increased dyspnoea perception (peak Borg and $\Delta$ Borg) in FE (figure 4). However, three

Table 2 Breathing pattern, ventilatory response to $\mathrm{CO}_{2}, \mathrm{P}_{01}$ and dyspnoea perception (Borg scale) at baseline (prior to rebreathing)

\begin{tabular}{|c|c|c|c|c|}
\hline & $\begin{array}{l}\text { Controls } \\
\mathrm{N}=10\end{array}$ & $\begin{array}{l}\text { COPD FE } \\
N=14\end{array}$ & $\begin{array}{l}\text { COPD IE } \\
N=20\end{array}$ & $\begin{array}{l}p \text { Value } \\
\text { FE vs IE }\end{array}$ \\
\hline Respiratory rate, /min & $14.60 \pm 3.97$ & $16.60 \pm 3.48$ & $15.75 \pm 4.61$ & 0.5 \\
\hline Tidal volume, L & $1.18 \pm 0.32$ & $1.24 \pm 0.37$ & $1.08 \pm 0.35$ & 0.3 \\
\hline Minute ventilation $\left(\mathrm{V}_{\mathrm{E}}\right), \mathrm{L} / \mathrm{min}$ & $16.79 \pm 4.70$ & $19.78 \pm 3.61$ & $16.50 \pm 4.58$ & 0.1 \\
\hline Tidal volume/inspiratory Capacity, \% & - & $0.6 \pm 0.2$ & $0.6 \pm 0.1$ & 0.5 \\
\hline $\mathrm{PetCO}_{2}, \mathrm{~mm} \mathrm{Hg}$ & $46.15 \pm 3.11$ & $49.23 \pm 4.35$ & $50.73 \pm 6.42$ & 0.2 \\
\hline $\mathrm{P}_{01}, \mathrm{~cm} \mathrm{H}_{2} \mathrm{O}$ & $1.13 \pm 0.48$ & $3.88 \pm 2.08^{*}$ & $2.15 \pm 1.20^{*}$ & $<0.001$ \\
\hline Borg score & $0.20 \pm 0.42$ & $0.82 \pm 1.03$ & $0.97 \pm 1.97$ & 0.3 \\
\hline
\end{tabular}


Table 3 Breathing pattern, ventilatory response to $\mathrm{CO}_{2}, \mathrm{P}_{01}$ and dyspnoea perception (Borg scale) at peak rebreathing

\begin{tabular}{|c|c|c|c|c|}
\hline Test duration, min & $3.76 \pm 0.27$ & $3.80 \pm 0.38$ & $3.95 \pm 0.47$ & 0.3 \\
\hline Respiratory rate, /min & $18.48 \pm 5.95$ & $21.57 \pm 5.35$ & $21.32 \pm 4.31$ & 0.2 \\
\hline Tidal volume, $\mathrm{L}$ & $2.29 \pm 0.98$ & $1.38 \pm 0.42^{*}$ & $1.43 \pm 0.41$ * & 0.02 \\
\hline $\begin{array}{l}\Delta \text { Tidal volume (vs } \\
\text { baseline), } \mathrm{L}\end{array}$ & $1.11 \pm 0.76$ & $0.14 \pm 0.36^{*}$ & $0.34 \pm 0.39 *$ & $<0.005$ \\
\hline $\begin{array}{l}\text { Minute ventilation }\left(V_{E}\right) \text {, } \\
L / \min \end{array}$ & $40.13 \pm 18.11$ & $28.63 \pm 7.95$ & $30.48 \pm 10.13$ & 0.3 \\
\hline$\Delta \mathrm{V}_{\mathrm{E}}$ (vs baseline), $\mathrm{L} / \mathrm{min}$ & $23.34 \pm 18.22$ & $8.85 \pm 6.58^{*}$ & $13.98 \pm 10.16$ & $<0.05$ \\
\hline $\mathrm{PetCO}_{2}, \mathrm{~mm} \mathrm{Hg}$ & $54.53 \pm 4.31$ & $61.11 \pm 5.30 *$ & $62.49 \pm 6.71 *$ & $<0.01$ \\
\hline$\Delta \mathrm{V}_{\mathrm{E}} / \Delta \mathrm{PetCO}_{2}$ & $2.78 \pm 1.29$ & $0.75 \pm 0.56^{*}$ & $1.25 \pm 0.94^{*}$ & $<0.001$ \\
\hline Borg score & $3.6 \pm 1.57$ & $6.35 \pm 1.54^{*}$ & $2.32 \pm 1.94^{*}$ & $<0.001$ \\
\hline$\Delta$ Borg (vs baseline) & $3.40 \pm 1.50$ & $5.53 \pm 1.42 *$ & $1.35 \pm 0.82^{*}$ & $<0.001$ \\
\hline
\end{tabular}

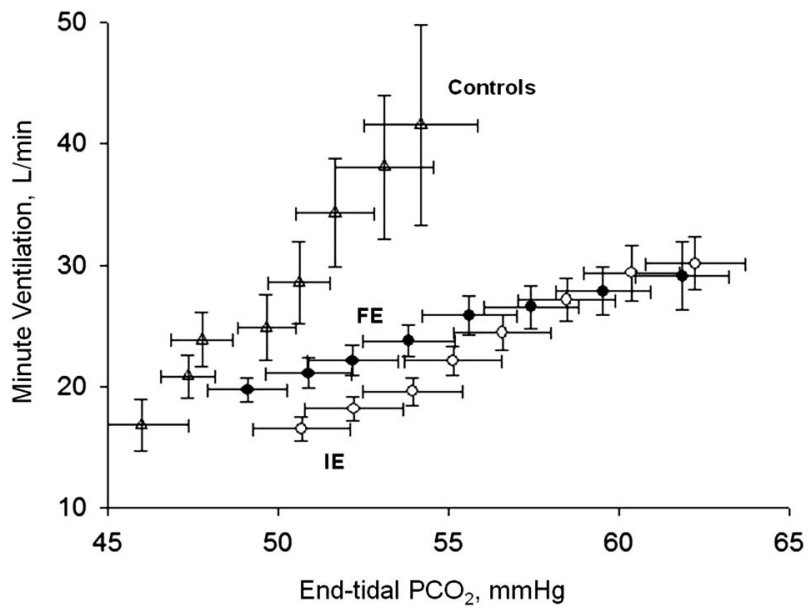

Figure 2 Hyperoxic ventilatory response to hypercapnia (mean \pm SEM) in controls and COPD patients with frequent exacerbation (FE) and infrequent exacerbation (IE). For further explications, see text.

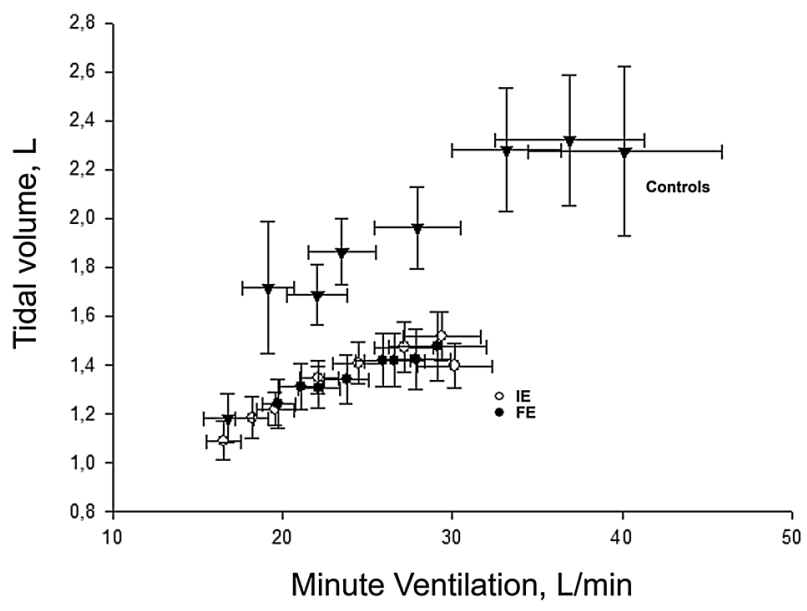

Figure 3 Relationship between minute ventilation and tidal volume during $\mathrm{CO}_{2}$ rebreathing (mean $\pm \mathrm{SEM}$ ) in controls and COPD patients with frequent exacerbation (FE) and infrequent exacerbation (IE). For further explanations, see text.

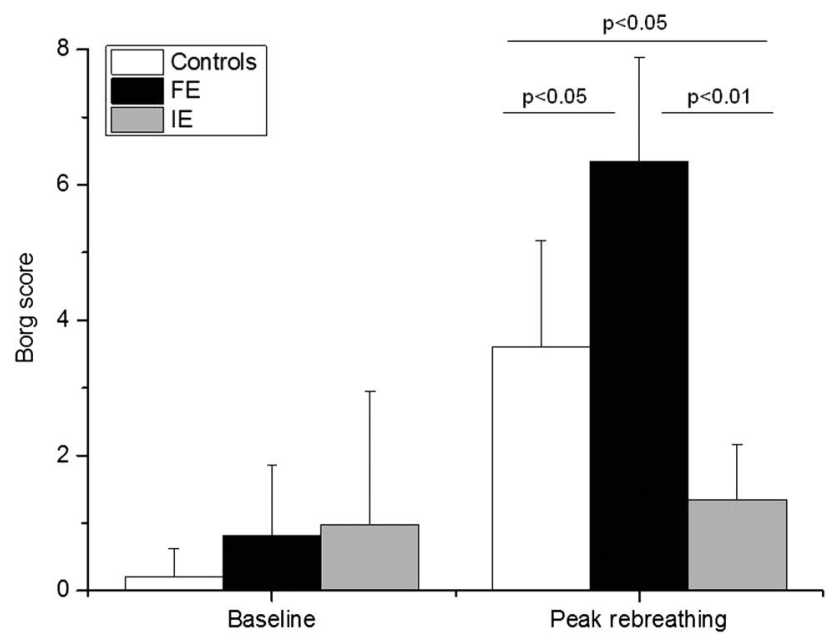

Figure 4 Mean $( \pm S D)$ values of the Borg score at baseline (before rebreathing) and at peak rebreathing in controls, frequent exacerbation (FE) and infrequent exacerbation (IE). For further explanations, see text.

observations argue against this possibility. First, both groups were carefully matched at baseline for age, gender and, specially, lung function variables, which were not significantly different between them (table 1). Second, as shown in figure 3, the $V_{T} / V_{E}$ relationship during rebreathing was not different in FE and IE (although clearly different in both groups vs controls, as anticipated), suggesting that differential dynamic hyperinflation during $\mathrm{CO}_{2}$ rebreathing was not a major operating mechanism underlying the different dyspnoea perception observed in FE and IE (figure 4). Finally, as shown in figure 2, it is not only that dyspnoea perception was increased in FE versus controls; it is that it was blunted in IE versus controls. This therefore supports the possibility of central misperception of dyspnoea in these two groups of patients with COPD. On the one hand, overperceiver patients might be expected to suffer greater activity-related dyspnoea and to be more prone to AECOPD-like events (ie, FE). On the other, poor perceivers may be less likely to seek prompt attention (ie, IE) and, therefore, contribute to the pathogenesis of the so-called 'unreported exacerbations'. ${ }^{22}$ Poor symptom perception has been previously reported in patients with asthma. ${ }^{23}{ }^{24}$ Additionally, as recently published, engagement of the brain is important in the perception of dyspnoea through many different circuits. ${ }^{25-27}$

$\mathrm{P}_{0.1}$ is the pressure generated in the first $100 \mathrm{~ms}$ of inspiration against an occluded airway. ${ }^{14}$ It is a crude estimation of the central respiratory drive. ${ }^{14}$ In keeping with previous reports, ${ }^{16}$ we also observed that $\mathrm{P}_{0.1}$ values at baseline (before rebreathing) were significantly higher in both groups of patients with COPD than in controls but, interestingly, we also found that they were higher $(\mathrm{p}<0.01)$ in FE than IE (table 2). This suggests increased respiratory neural drive in FE compared with controls and IE. In the setting of similar spirometric and gas exchange abnormalities in $\mathrm{FE}$ and IE, the increased $\mathrm{P}_{0.1}$ in $\mathrm{FE}$ points again to possible differences in respiratory control or in the sensory processing of perceived respiratory discomfort between the two groups of patients with COPD. ${ }^{20} 21$

It is well established that patients with COPD may have different MIP-MEP values than controls due to a variety of reasons (lung hyperinflation, malnutrition, hypoxia, etc). In keeping with this, we observed a trend towards lower values in both COPD groups (table 1), but differences were not statistically significant, so we do not think that they can explain our results. 
Our study has some limitations that deserve comment. First, it includes a relatively small number of subjects, so it has to be replicated in other populations. Second, all patients included in the study were of Caucasian origin, so our result cannot be directly extrapolated to other ethnicities. Third, the patients included in the study were mostly males and no one has significant baseline chronic hypercapnia $\left(\mathrm{PaCO}_{2} 39.85 \mathrm{~mm} \mathrm{Hg}\right)$. Finally, there is a trend towards worse lung function, more subjects in higher GOLD stages and more gas trapping between the FE and IE groups. Because the sample size is small, these differences were not statistically significant. However, if a larger sample size were obtained, these differences may have indeed become statistically different.

In summary, our study shows that COPD patients with FE and IE have different resting inspiratory neural drive and different perceptual responses to chemostimulation despite similar abnormalities in respiratory mechanics and pulmonary gas exchange. These differences in perception of dyspnoea intensity at a standardised stimulus may have important clinical implications since they open the possibility of potential therapeutic interventions into the pathways that control the perception of dyspnoea to improve quality of life in patients with COPD. We acknowledge, however, that this requires further research on the cortical substrates for the perception of dyspnoea.

\section{Author affiliations \\ ${ }^{1}$ Servei de Pneumologia, Institut Clínic Respiratori, Hospital Clínic, Barcelona, Spain ${ }^{2}$ Department of Medical and Surgical Sciences, Institute of Respiratory Disease, University of Foggia, Foggia, Italy \\ ${ }^{3}$ Fundació Clínic per la Recerca Biomèdica, Hospital Clínic, Barcelona, Spain ${ }^{4}$ Centro de Investigación Biomédica en Red de Enfermedades Respiratorias (CIBERES), Spain \\ Institut d'Investigacions Biomédiques August Pi i Sunyer (IDIBAPS), Universitat de Barcelona, Barcelona, Spain \\ ${ }^{6}$ Pulmonary Division, Brigham and Women's Hospital, Harvard Medical School, Boston, Massachusetts, USA \\ ${ }^{7}$ Respiratory Investigation Unit and Laboratory of Clinical Exercise Physiology, Queen's University and Kingston General Hospital, Kingston, Ontario, Canada}

Acknowledgements The authors thank the participating patients and controls for their willingness to contribute to medical research.

Contributors GS, IB and EA contributed equally to the article. Conception and design: AA. Field work: GS, IB, EA, FB, CG. Analysis and interpretation: all. Drafting the manuscript for important intellectual content: all.

Funding The University of Foggia supported GS during her fellowship in Hospital Clinic, Barcelona (Spain)

Competing interests None declared.

Ethics approval Ethics Committee of the Hospital Clínic, Universitat de Barcelona (protocol HCP/14/329).

Provenance and peer review Not commissioned; externally peer reviewed.

\section{REFERENCES}

1 Vestbo J, Hurd SS, Agustí A, et al. Global strategy for the diagnosis, management and prevention of chronic obstructive pulmonary disease, GOLD executive summary. Am J Respir Crit Care Med 2013;187:347-65.
2 Celli BR, Decramer M, Wedzicha JA, et al. An official American Thoracic Society/ European Respiratory Society statement: research questions in COPD. Eur Respir J 2015;45:879-905.

3 Hurst JR, Vestbo J, Anzueto A, et al. Susceptibility to exacerbation in chronic obstructive pulmonary disease. N Engl J Med 2010;363:1128-38.

4 Rodriguez-Roisin R. Toward a consensus definition for COPD exacerbations. Chest 2000;117(Suppl 2):398S-401S.

5 Scioscia G, Blanco I, Burgos F, et al. Breathlessness perception in COPD: Relationship with Exacerbation Frequency. Am J Respir Crit Care Med 2015;191: A2535.

6 Miller MR, Hankinson J, Brusasco V, et al. Standardisation of spirometry. Eur Respir J 2005;26:319-38

7 Wanger J, Clausen JL, Coates A, et al. Standardisation of the measurement of lung volumes. Eur Respir J 2005;26:511-22.

8 Macintyre N, Crapo RO, Viegi G, et al. Standardisation of the single-breath determination of carbon monoxide uptake in the lung. Eur Respir $J$ 2005;26:720-35.

9 Roca J, Burgos F, Sunyer J, et al. References values for forced spirometry. Group of the European Community Respiratory Health Survey. Eur Respir J 1998:11:1354-62.

10 Roca J, Burgos F, Barberà JA, et al. Prediction equations for plethysmographic lung volumes. Respir Med 1998;92:454-60.

11 Roca J, Rodriguez-Roisin R, Cobo E, et al. Single-breath carbon monoxide diffusing capacity (DLCO) prediction equations for a Mediterranean population. Am Rev Respir Dis 1990;141:1026-32.

12 ATS/ERS Statement on respiratory muscle testing. Am J Respir Crit Care Med 2002;166:518-624.

13 Duffin J. Measuring the respiratory chemoreflexes in humans. Respir Physiol Neurobiol 2011:177:71-9.

14 Clausen JL. Pulmonary function testing. Guidelines and controversies. Equipment, methods and normal values. 1st edn. Orlando: Grune \& Stratton, Inc., 1984:1-338.

15 Borg GA. Psychophysical bases of perceived exertion. Med Sci Sports Exerc 1982:14:377-81.

16 Marin JM, Montes de OM, Rassulo J, et al. Ventilatory drive at rest and perception of exertional dyspnea in severe COPD. Chest 1999;115:1293-300.

17 Altose MD, McCauley WC, Kelsen SG, et al. Effects of hypercapnia and inspiratory flow-resistive loading on respiratory activity in chronic airways obstruction. J Clin Invest 1977:59:500-7.

18 Montes de Oca M, Celli BR. Mouth occlusion pressure, CO2 response and hypercapnia in severe chronic obstructive pulmonary disease. Eur Respir J 1998;12:666-71.

19 O'Donnell DE, Bertley JC, Chau LK, et al. Qualitative aspects of exertional breathlessness in chronic airflow limitation: pathophysiologic mechanisms. Am J Respir Crit Care Med 1997:155:109-15.

20 Parshall MB, Schwartzstein RM, Adams L, et al. An official American Thoracic Society Statement: update on the mechanisms, assessment, and management of dyspnea. Am J Respir Crit Care Med 2012;185:435-52.

21 Laviolette L, Laveneziana P. Dyspnoea: a multidimensional and multidisciplinary approach. Eur Respir J 2014:43:1750-62.

22 Seemungal TA, Donaldson GC, Bhowmik A, et al. Time course and recovery of exacerbations in patients with chronic obstructive pulmonary disease. Am J Respir Crit Care Med 2000;161:1608-13.

23 Laforest L, El Hasnaoui A, Pribil C, et al. Asthma patients' perception of their ability to influence disease control and management. Ann Allergy Asthma Immunol 2009;102:378-84.

24 Davis SQ, Permutt Z, Permutt $S$, et al. Perception of airflow obstruction in patients hospitalized for acute asthma. Ann Allergy Asthma Immunol 2009;102:455-61.

25 Herigstad M, Hayen A, Evans $E$, et al. Dyspnea-related cues engage the prefrontal cortex: evidence from functional brain imaging in COPD. Chest 2015;148:953-61.

26 Yu L, De Mazancourt M, Hess A, et al. Functional connectivity and information flow of the respiratory neural network in chronic obstructive pulmonary disease. Hum Brain Mapp 2016:37:2736-54.

27 Gifford AH, Mahler DA, Waterman LA, et al. Neuromodulatory effect of endogenous opioids on the intensity and unpleasantness of breathlessness during resistive load breathing in COPD. COPD 2011;8:160-6. 